\title{
Testing the anterior pituitary: hypoglycaemia produced by continuous intravenous insulin infusion
}

\author{
GEOFFREY H NEWMAN, IAN A MACDONALD, SIMON P ALLISON
}

\begin{abstract}
The response of growth hormone, cortisol, and catecholamines to hypoglycaemia produced by a continuous intravenous infusion of insulin was investigated in 10 normal subjects and 15 patients with pituitary disease. The insulin infusion rate was started at $2 \mathrm{U} /$ hour for adolescents, $4 \mathrm{U}$ / hour for adults, and $6 \mathrm{U} /$ hour for patients with acromegaly. If required the rate was increased during the test depending on changes in blood glucose, measured by a Reflomat with low reading glucose oxidase strips. Stopping the infusion when the blood glucose concentration had fallen to $2.0 \mathrm{mmol} / 1(36 \mathrm{mg} / 100 \mathrm{ml})$ resulted in a maximum further fall of $0.7 \mathrm{mmol} / 1(13 \mathrm{mg} / 100 \mathrm{ml})$ and a subsequent spontaneous rise in blood glucose concentration. The rise was identical in normal subjects and in patients with hypopituitarism, further evidence that pituitary hormones-in contrast to glucagon and catecholamines-are relatively unimportant in the recovery from hypoglycaemia. The only patient who required intravenous glucose to restore normoglycaemia was a patient with longstanding insulin dependent diabetes. A comparison with the conventional bolus injection test showed that continuous intravenous insulin infusion was more reliable in producing adequate but not excessive hypoglycaemia and the hormone responses were equivalent.
\end{abstract}

The continuous intravenous insulin infusion may offer particular advantages in the investigation of growth hormone deficiency.

University Hospital, Nottingham NG7 2UH

GEOFFREY H NEWMAN, MRCP, registrar in medicine

IAN A MACDONALD, PHD, lecturer in physiology

SIMON P ALLISON, MD, FRCP, consultant physician

Correspondence to: Dr Simon P Allison.

\section{Introduction}

The capacity of the pituitary to secrete growth hormone and adreno corticotrophic hormone is commonly assessed by provoking hypoglycaemia with a single bolus injection of insulin at a dose of $0 \cdot 1-0 \cdot 3$ units per kilogram body weight according to the expected degree of insulin resistance. ${ }^{1}$ The rate and extent of the fall in blood glucose concentration is not always predictable. An excessive dose may produce severe hypoglycaemic symptoms necessitating an infusion of glucose whereas an inadequate dose in an insulin resistant patient with obesity, Cushing's syndrome, or acromegaly necessitates a further dose or a repeat of the test.

The introduction of a simple and reliable method of measuring blood glucose concentration repeatedly by the bedside, and experience with measurement of the endocrine response to continuous insulin infusion in normal subjects, ${ }^{2}$ led us to the belief that continuous infusion might result in a more reliable test of pituitary function than bolus injection of insulin. If the blood glucose concentration does not fall adequately with a low dose infusion, the rate of infusion can be increased, producing a smooth and slow fall that can be arrested simply by stopping the insulin infusion. In normal subjects infusion of insulin controlled by repeated estimations of blood glucose concentrations produced far fewer symptoms than a bolus injection of insulin." The fall in blood glucose concentration was predictable and the hormone responses were equivalent, growth hormone and cortisol concentrations having reached their maximum values within 40 minutes of hypoglycaemia defined as a glucose concentration of $2.0 \mathrm{mmol} / \mathrm{l}(36 \mathrm{mg} / 100 \mathrm{ml})$. We present the results of this test in patients with pituitary disease and in normal subjects and compare these with results of the conventional insulin tolerance test in some of the patients.

\section{Patients and methods}

Ten normal subjects aged 22-59 years and 15 patients aged 16-67 years were studied. Table I shows the diagnoses and current drug treatment of the patients. All subjects and patients gave informed consent. All subjects and patients underwent the continuous infusion test and in addition hypoglycaemia was induced in seven patients using the conventional insulin tolerance test with a bolus dose of $0.1 \mathrm{U} / \mathrm{kg}$ 
TABLE I-Diagnosis and current treatment of 15 patients with pituitary disorders

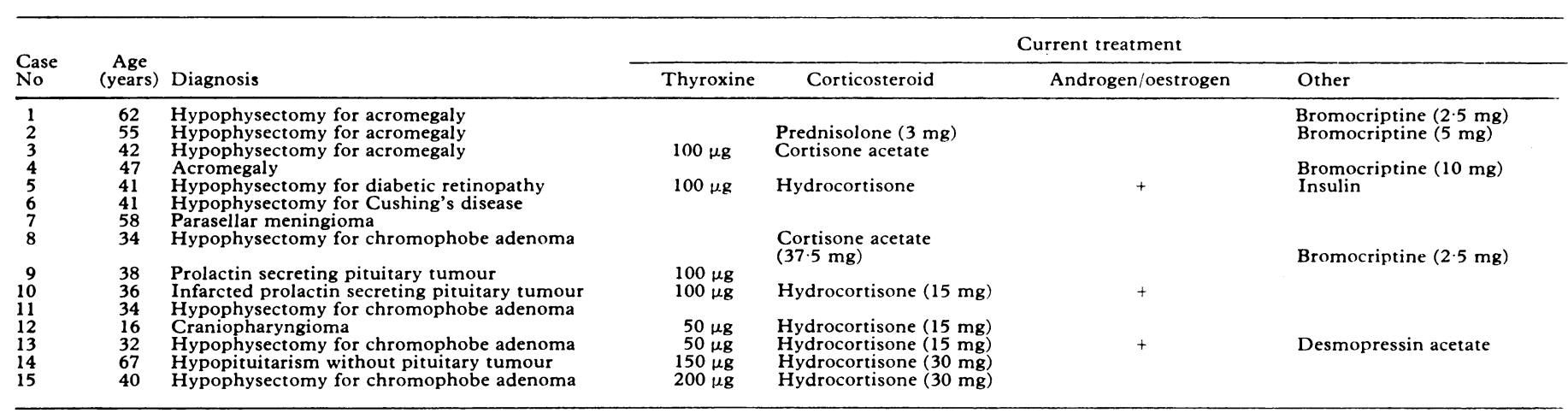

intravenously. These two tests were separated by an interval of at least one week. Tests were performed in the morning after an overnight fast. All drugs except insulin were withheld after the 9 am dose of hydrocortisone on the previous day. Glucose, glucagon, and hydrocortisone were always available.

\section{CONTINUOUS INTRAVENOUS INSULIN INFUSION}

The subjects were recumbent throughout the procedure, and an indwelling cannula was inserted into a vein in each arm. Basal samples for measurement of glucose, cortisol, growth hormone, noradrenaline, and adrenaline concentrations were taken 30 minutes and 45 minutes after cannulation. An estimate of blood glucose concentration was made with a Reflomat using low reading (Hypoglycaemie, Boehringer Ltd), strips. The measurements were duplicated in the laboratory by a glucose oxidase autoanalyser technique.

The insulin infusion was delivered by a Vickers syringe pump at an initial rate of $4 \mathrm{U} /$ hour in the 10 normal subjects and 11 of the patients. In anticipation of insulin resistance the patient with diabetes and two with acromegaly were started on $6 \mathrm{U} /$ hour. One patient who was underweight (case $12,42 \mathrm{~kg}$ ) was started on $2 \mathrm{U} /$ hour. Ten units of Novo monocomponent soluble insulin $(1 \mathrm{U} / \mathrm{ml})$ and $5 \mathrm{ml}$ of salt free albumin were added to the syringe and the volume was made up to $50 \mathrm{ml}$ with $0.9 \%$ sodium chloride. The infusion was started after the second basal sample had been taken. The blood glucose concentration was estimated every 10 minutes using the Reflomat and the rate of infusion was altered if necessary, depending on readings taken after 40 minutes and 60 minutes of insulin infusion. If the blood glucose was greater than $2.0 \mathrm{mmol} / 1(36 \mathrm{mg} / 100 \mathrm{ml})$ after 40 minutes of infusion, the rate was increased to $8 \mathrm{U} /$ hour. A further increase to $12 \mathrm{U} /$ hour was made if, after 60 minutes of infusion, the blood glucose was greater than $2.0 \mathrm{mmol} / \mathrm{l}(36 \mathrm{mg} /$ $100 \mathrm{ml}$ ).

The insulin infusion was stopped when the blood glucose as estimated by the Reflomat had fallen to $2.0 \mathrm{mmol} / 1(36 \mathrm{mg} / 100 \mathrm{ml})$. Samples for estimation of glucose (sodium fluoride), growth hormone, cortisol, noradrenaline, and adrenaline (lithium heparin) concentrations were taken 10,20,30, and 40 minutes after the infusion had been stopped. For the hormone assays the blood was centrifuged and the supernatant frozen until analysis. All the subjects experienced mild symptoms of hypoglycaemia and a meal rich in carbohydrates was given to them at the end of the test.

\section{CONVENTIONAL INSULIN TOLERANCE TEST}

All patients, except one with acromegaly, had undergone standard thyrotrophin releasing hormone and gonadotrophin releasing hormone tests on a previous occasion, although it is possible to combine these with the insulin infusion test.

The seven patients undergoing a conventional insulin tolerance test were studied under identical conditions to those of the continuous infusion except that only one intravenous cannula was used. Monocomponent insulin $(0 \cdot 1 \mathrm{U} / \mathrm{kg}$ body weight) was given as a single bolus intravenously, the dose recommended for patients with suspected hypopituitarism.

\section{ASSAY TECHNIQUE}

Growth hormone was measured by radioimmunoassay according to the method recommended by the Supra Regional Assay Service; the variation between batches of assay is $4.4 \%$ at $36 \mathrm{mU} / \mathrm{l}$. Cortisol was measured using the Amerlex cortisol radioimmunoassay kit; the variation between batches is $5.7 \%$ at $325 \mathrm{nmol} / 1(11.8 \mu \mathrm{g} / 100 \mathrm{ml})$.

Adrenaline and noradrenaline were measured by extraction from $1 \mathrm{ml}$ of plasma, separated by high performance liquid chromatography, and quantified by electrochemical detection. ${ }^{3}$ Intra-assay coefficient of variation for the measurement of catecholamines during hypoglycaemia is $4 \%$ and the interassay coefficient of variation is $10 \%$.

\section{STATISTICS}

The differences in blood glucose and hormone concentrations, $(a)$ between normal subjects and patients and $(b)$ comparing the continuous infusion with the bolus injection of insulin, were tested by Student's $t$ test.

\section{Results}

For the purpose of expressing results the 15 patients were divided retrospectively into three groups, based on the results of the present study rather than the results of previous pituitary function tests. The groups were as follows: patients with acromegaly $(n=4)$, three of whom had undergone previous transethmoidal hypophysectomy without complete cure; patients with "moderate hypopituitarism" $(n=8)$; and those with "severe hypopituitarism" $(n=3)$. Patients with severe hypopituitarism had suboptimal responses of both cortisol and growth hormone secretion to hypoglycaemia (peak cortisol concentration $<500 \mathrm{nmol} / 1(18 \mu \mathrm{g} / 100 \mathrm{ml})$, maximum rise in cortisol $<200$ $\mathrm{nmol} / \mathrm{l}(7 \mu \mathrm{g} / 100 \mathrm{ml})$, peak growth hormone hormone $<20 \mathrm{mU} / \mathrm{l})$. Those with moderate hypopituitarism had a normal response of either growth hormone or cortisol to hypoglycaemia.

\section{CONTINUOUS INFUSION TEST}

All subjects experienced adequate hypoglycaemia (blood glucose concentration less than $2.0 \mathrm{mmol} / 1(36 \mathrm{mg} / 100 \mathrm{ml})$ ) and were seen to sweat. The mean heart rate before starting the insulin infusion was $60 /$ min (range 42-76) and the mean maximal heart rate during the test was $76 /$ min (range 54-91). Plasma adrenaline and noradrenaline concentrations were measured in 11 patients and seven controls (table II). Basal concentrations of plasma catecholamines were higher in the patients than in controls but there was no difference in mean maximal concentrations or mean increase above basal between the two groups. In nine of the patients, including two with acromegaly, the patient with diabetes, and the lightest patient $(42 \mathrm{~kg}$ ) hypoglycaemia was induced within 40 minutes of insulin infusion. The other six patients required an increase in the rate of infusion after 40 minutes to $8 \mathrm{U} /$ hour, and in three of these (two with acromegaly) a subsequent rise to $12 \mathrm{U} /$ hour after 60 minutes of insulin infusion. Figure 1 compares the fall in blood glucose concentration with time for the normal subjects and the 
TABLE II-Plasma adrenaline and noradrenaline concentrations in 11 patients and seven controls. Results are means (SEM)

\begin{tabular}{lcc}
\hline & Controls $(\mathrm{n}=7)$ & Patients $(\mathrm{n}=11)$ \\
\hline Adrenaline (nmol/l): & $0.56(0.12)$ & \\
$\quad$ Basal & $2.93(0.88)$ & $1.12(0.20)$ \\
Maximum & $2.08(0.87)$ & $4.78(0.69)$ \\
Increment & $+1.14(0.18)$ & $3.65(0.62)$ \\
Noradrenaline (nmol/l): & $3.03(0.35)$ & $1.89(0.20)$ \\
Basal & $1.94(0.40)$ & $3.63(0.66)$ \\
Maximum & & $1.64(0.55)$ \\
Increment & & \\
\hline
\end{tabular}

- 0.05 . 05.

Conversion: SI to traditional units-Adrenaline : $1 \mathrm{nmol} / \mathrm{l} \approx 0.18 \mathrm{ng} / \mathrm{ml}$. Noradrenaline: $1 \mathrm{nmol} / \mathrm{l}=0.17 \mathrm{ng} / \mathrm{ml}$.

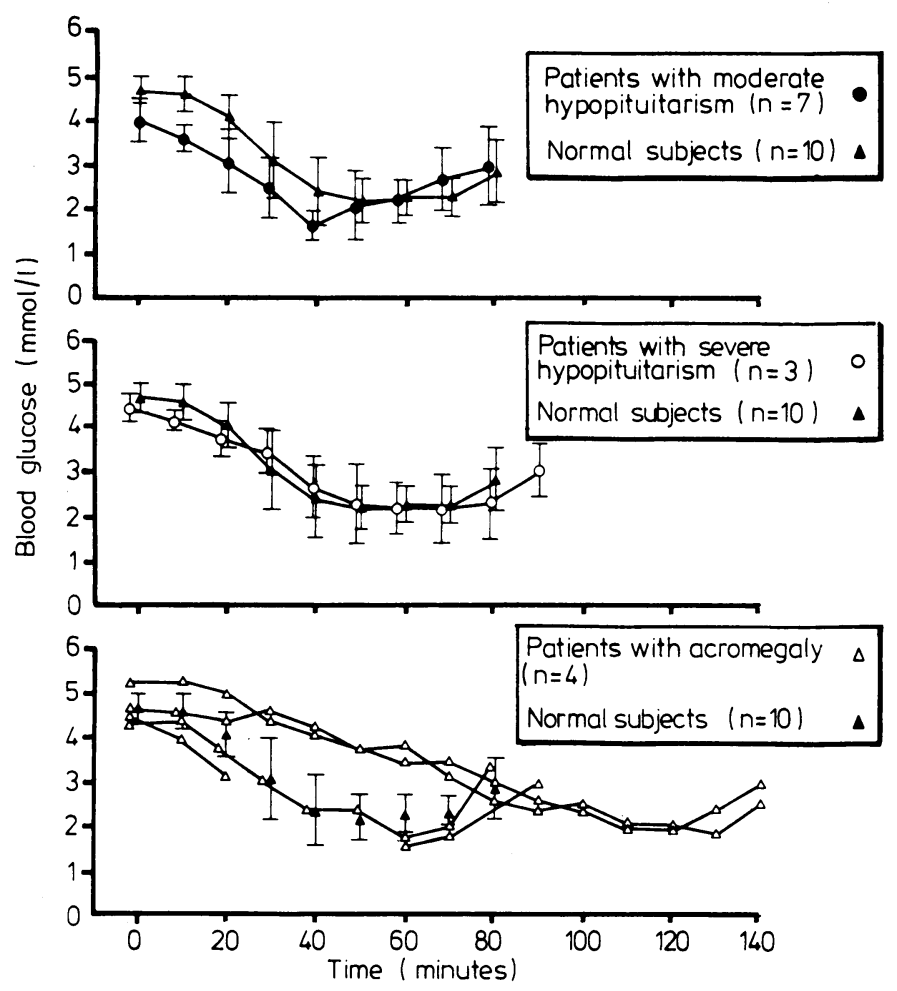

FIG 1-Mean (SEM) fall in blood glucose concentration during insulin infusion in 14 patients (excluding one with diabetes) and in 10 normal subjects.

Conversion: $S I$ to traditional units-Glucose: $1 \mathrm{mmol} / 1 \approx 18 \mathrm{mg} / 100 \mathrm{ml}$.

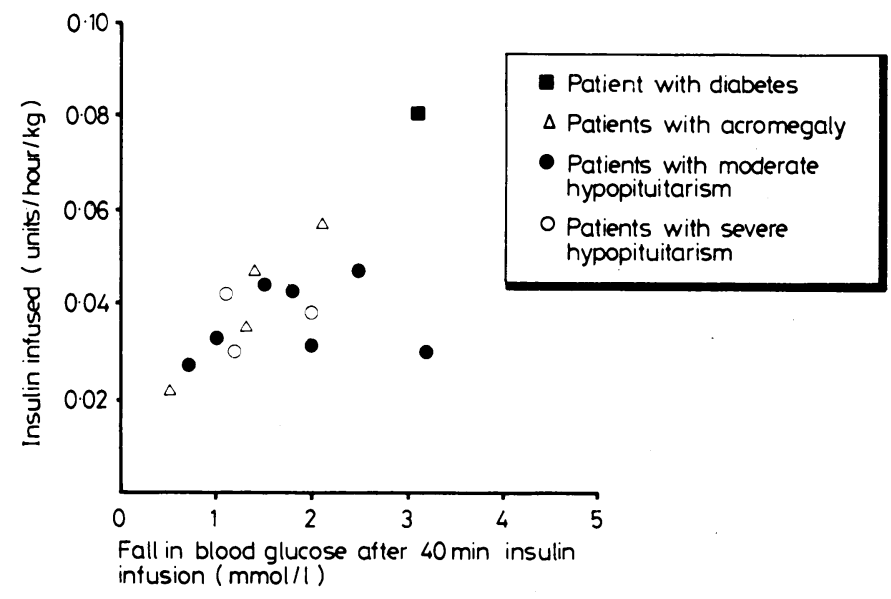

FIG 2-Relation between amount of insulin infused and fall in blood glucose concentration after $\mathbf{4 0}$ minutes of insulin infusion.

Conversion: SI to traditional units-Glucose: $1 \mathrm{mmol} / 1 \approx 18 \mathrm{mg} / 100 \mathrm{ml}$. patients with acromegaly, moderate and severe hypopituitarism. Figure 2 shows the relation between the amount of insulin infused per kilogram body weight and the fall in blood glucose after 40 minutes of insulin infusion. The Reflomat strips gave consistent results; the correlation coefficient between blood glucose concentration measured by the Reflomat and by the laboratory glucose oxidase method was 0.90 $(n=145)$. When the insulin infusion was stopped the blood glucose continued to fall by a further $0.70 \mathrm{mmol} / 1(13 \mathrm{mg} / 100 \mathrm{ml})$ at the most (lowest mean plasma glucose concentration for all patients 1.71 (SEM 0.07) $\mathrm{mmol} / \mathrm{l}(31(1) \mathrm{mg} / 100 \mathrm{ml})$ ); it then rose to normal values in all except the diabetic patient, who required intravenous glucose. Even the patients with more severe hypopituitarism showed glucose curves that were not significantly different from those for the normal subjects. In no case had the test to be curtailed or repeated because of severe symptoms or unsatisfactory results.

Figure 3 shows the growth hormone and cortisol responses. The patients with acromegaly had high basal concentrations of growth hormone, which rose slightly with hypoglycaemia. Table III shows the maximal growth hormone and cortisol responses of the 15 patients after the continuous insulin infusion. Most patients with moderate hypopituitarism had impaired responses of growth hormone with normal responses of cortisol. The results of thyrotrophin releasing hormone and gonadotrophin releasing hormone tests are also shown.

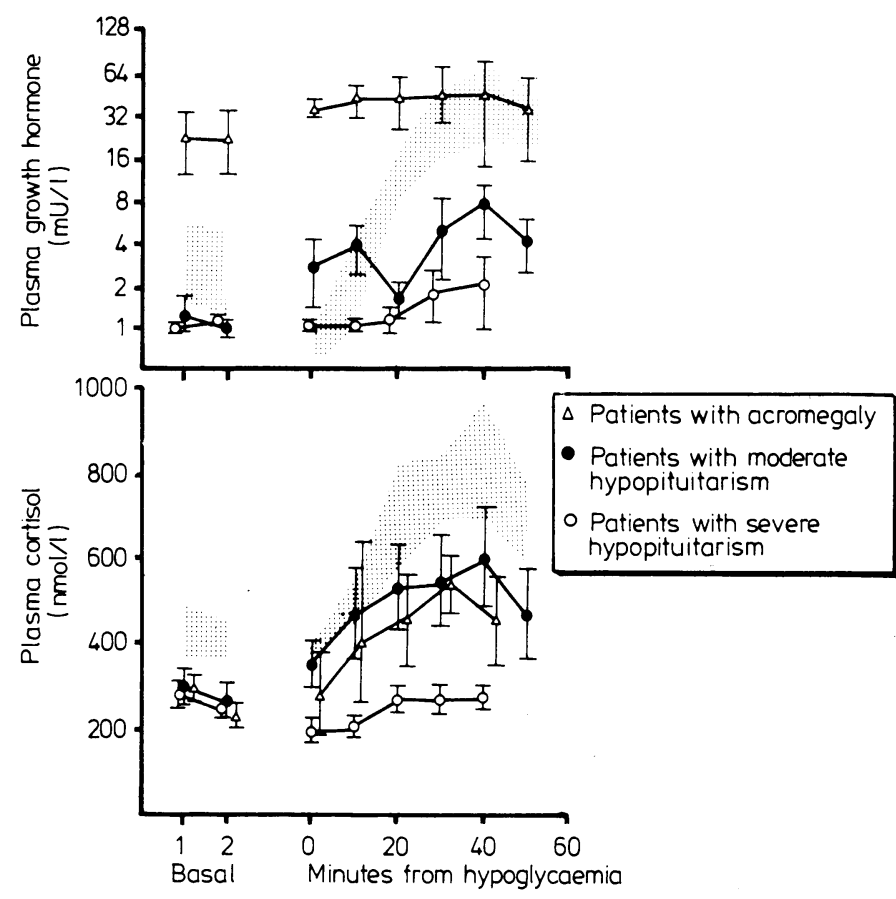

FIG 3-Plasma growth hormone and cortisol concentrations after hypoglycaemia produced by intravenous insulin infusion. Values are mean (SEM) and shaded areas represent mean ( 1 SEM) in normal subjects $(n=10)$.

Conversion: SI to traditional units-Cortisol: $1 \mathrm{nmol} / 1 \approx 0.04 \mu \mathrm{g} / 100 \mathrm{ml}$.

\section{COMPARISON WITH CONVENTIONAL INSULIN TOLERANCE TEST}

The group of seven patients undergoing both tests comprised one with acromegaly, four with moderate hypopituitarism, and two with severe hypopituitarism. Two patients required a second bolus injection of insulin $(0.05 \mathrm{U} / \mathrm{kg})$ because they did not appear to be clinically hypoglycaemic. In spite of this second injection neither patient was seen to sweat and the lowest plasma glucose achieved was $2.3 \mathrm{mmol} / \mathrm{l}$ $(41 \mathrm{mg} / 100 \mathrm{ml})$ in one and $2 \cdot 2 \mathrm{mmol} / 1(40 \mathrm{mg} / 100 \mathrm{ml})$ in the other. Table IV gives results in the remaining five patients and compares the nadir of plasma glucose concentration and the hormonal responses to hypoglycaemia produced either by continuous intravenous insulin infusion or by the conventional insulin tolerance test. The mean nadir of plasma glucose concentration was significantly lower in the bolus injection test $(\mathrm{p}<0.02)$. There were no significant differences between peak concentrations or the increment for growth hormone, cortisol, adrenaline, and noradrenaline. 
TABLE III-Maximum responses of growth hormone and cortisol to hypoglycaemia produced by intravenous insulin infusion

\begin{tabular}{|c|c|c|c|c|}
\hline \multirow[b]{2}{*}{$\begin{array}{l}\text { Case } \\
\text { No }\end{array}$} & \multicolumn{2}{|c|}{ Results of tests } & \multirow[b]{2}{*}{$\begin{array}{l}\text { Maximum growth } \\
\text { hormone }\left(\mathrm{mU}_{/} \mathrm{l}\right)\end{array}$} & \multirow[b]{2}{*}{$\underset{(\mathrm{nmol} / \mathrm{l})}{\operatorname{Maximum} \text { cortisol }}$} \\
\hline & $\begin{array}{l}\text { Thyrotrophin } \\
\text { releasing hormon }\end{array}$ & $\begin{array}{l}\text { Gonadotrophin } \\
\text { e releasing hormone }\end{array}$ & & \\
\hline \multicolumn{5}{|c|}{ Patients with acromegaly } \\
\hline $\begin{array}{l}1 \\
2 \\
3 \\
4\end{array}$ & $\begin{array}{l}\text { Normal } \\
\text { Normal } \\
\text { Abnormal }\end{array}$ & $\begin{array}{l}\text { Normal } \\
\text { Normal } \\
\text { Abnormal }\end{array}$ & $\begin{array}{r}32 \cdot 0 \\
16 \cdot 8 \\
59 \cdot 0 \\
102 \cdot 0\end{array}$ & $\begin{array}{l}712 \\
552 \\
436 \\
566\end{array}$ \\
\hline \multicolumn{5}{|c|}{ Patients with moderate hypopituitarism } \\
\hline $\begin{array}{r}5 \\
6 \\
7 \\
8 \\
9 \\
10 \\
11 \\
12\end{array}$ & $\begin{array}{l}\text { Abnormal } \\
\text { Normal } \\
\text { Normal } \\
\text { Normal } \\
\text { Abnormal } \\
\text { Abnormal } \\
\text { Normal } \\
\text { Abnormal }\end{array}$ & $\begin{array}{l}\text { Abnormal } \\
\text { Normal } \\
\text { Abnormal } \\
\text { Abnormal } \\
\text { Norrnal } \\
\text { Normal } \\
\text { Abnormal }\end{array}$ & $\begin{array}{r}7.1 \\
14.6 \\
5.9 \\
1.4 \\
1.8 \\
24.8 \\
3.3 \\
0.8\end{array}$ & $\begin{array}{l}773 \\
842 \\
593 \\
516 \\
974 \\
86 \\
813 \\
662\end{array}$ \\
\hline \multicolumn{5}{|c|}{ Patients with severe hypopituitarism } \\
\hline $\begin{array}{l}13 \\
14 \\
15\end{array}$ & $\begin{array}{l}\text { Normal } \\
\text { Abnormal } \\
\text { Abnormal }\end{array}$ & $\begin{array}{l}\text { Normal } \\
\text { Abnormal } \\
\text { Abnormal }\end{array}$ & $\begin{array}{l}3 \cdot 2 \\
2 \cdot 1 \\
1 \cdot 1\end{array}$ & $\begin{array}{l}317 \\
235 \\
326\end{array}$ \\
\hline
\end{tabular}

Conversion: SI to traditional units-Cortisol: $1 \mathrm{mmol} / \mathrm{l} \approx 0.04 \mu \mathrm{g} / 100 \mathrm{ml}$.

TABLE IV-Glucose and hormone responses to hypoglycaemia produced by continuous infusion or bolus injection of insulin. Results are means (SEM)

\begin{tabular}{|c|c|c|}
\hline & Continuous infusion & Bolus injection \\
\hline Lowest plasma glucose $(\mathrm{mmol} / \mathrm{l})$ & $*^{*} 1 \cdot 7(0 \cdot 14)$ & ${ }^{*} 1 \cdot 4(0 \cdot 14)$ \\
\hline $\begin{array}{l}\text { Growth hormone }(\mathrm{mU} / 1): \\
\text { Maximum } \\
\text { Increment }\end{array}$ & $\begin{array}{r}14.0(11.3) \\
2.2(0.9)\end{array}$ & $\begin{array}{l}5 \cdot 8(4 \cdot 2) \\
2 \cdot 1(1 \cdot 3)\end{array}$ \\
\hline $\begin{array}{l}\text { Cortisol }(\mathrm{nmol} / 1): \\
\text { Maximum } \\
\text { Increment }\end{array}$ & $\begin{array}{l}566(85) \\
245(70)\end{array}$ & $\begin{array}{l}584(86) \\
270(76)\end{array}$ \\
\hline $\begin{array}{l}\text { Adrenaline (nmol/1): } \\
\text { Maximum } \\
\text { Increment }\end{array}$ & $\begin{array}{l}3.65(1.07) \\
2.59(1.14)\end{array}$ & $\begin{array}{l}3.65(1.75) \\
2.68(1.80)\end{array}$ \\
\hline $\begin{array}{l}\text { Noradrenaline }(\mathrm{nmol} / \mathrm{l}) \text { : } \\
\text { Maximum } \\
\text { Increment }\end{array}$ & $\begin{array}{l}2.30(0.27) \\
0.46(0.31)\end{array}$ & $\begin{array}{l}4.54(1.51) \\
1.32(0.94)\end{array}$ \\
\hline
\end{tabular}

$* \mathrm{p}<0.02$.

Conversion: SI to traditional units-Glucose: $1 \mathrm{mmol} / 1 \approx 18 \mathrm{mg} / 100 \mathrm{ml}$. Cortisol: $1 \mathrm{nmol} / \mathrm{l} \approx 0.04 \mu \mathrm{kg} / 100 \mathrm{ml}$. Adrenaline: $1 \mathrm{nmol} / 1 \approx 0.18 \mathrm{ng} / \mathrm{ml}$. Noradrenaline: 1 $\mathrm{nmol} \approx 0.17 \mathrm{ng} / \mathrm{ml}$.

\section{Discussion}

Our findings in patients with pituitary disorders confirm those of previous work on normal subjects, ${ }^{2}$ showing that intravenous insulin infusion at $4 \mathrm{U} /$ hour produces a reliable and adequate hypoglycaemia in most people. If the infusion is stopped when the blood glucose concentration reaches $2.0 \mathrm{mmol} / 1(36 \mathrm{mg} / 100$ $\mathrm{ml})$ there is a maximum further fall of $0.7 \mathrm{mmol} / 1(13 \mathrm{mg} / 100$ $\mathrm{ml}$ ) followed by a spontaneous rise even in subjects with hypopituitarism. This rise may be related partly to autonomic counter regulation in view of the very high adrenaline concentrations produced in some of these patients, but the concentration of glucagon, which was not measured, may be even more important. Although diminished secretion of growth hormone and adenocorticotrophic hormone may confer insulin sensitivity, they are clearly of secondary importance in terms of counterregulation in a state of hypoglycaemia. ${ }^{4}$ Only the patient with diabetes required glucose to reverse his symptoms. This may be related to the inability of those with longstanding diabetes to secrete glucagon in response to hypoglycaemia. ${ }^{5}$

The continuous insulin infusion test took slightly longer to perform than the bolus injection but always produced the desired degree of hypoglycaemia at the first attempt. On the other hand, there was an appreciable failure rate with the traditional test. The nadir of plasma glucose concentration was significantly lower after the bolus insulin injection, whereas the growth hormone, cortisol, and catecholamine responses were comparable. This may explain the fact that although neuroglycopenic symptoms were experienced by all undergoing continuous infusion, fewer "hangover" symptoms were experienced with continuous infusion than with injection.
Hypoglycaemia caused by insulin infusion produced an adrenergic response in all subjects, as assessed by a rise in pulse rate, blood pressure, and plasma adrenaline and noradrenaline concentrations, which tended to be higher in the patients with hypopituitarism. After a short period of insulin infusion it is possible to identify those subjects whose blood glucose concentration is falling too slowly and to increase the rate of infusion by increments of $4 \mathrm{U} /$ hour. Smaller increments are ineffective, as additional insulin resistance appears to be conferred by the infusion itself, causing the ultimate insulin requirement to be more than if a slightly higher rate-say $6 \mathrm{U} / \mathrm{hour}$ - had been used in the first place. We therefore recommend that if insulin resistance is expected, as in acromegaly or obesity, the initial infusion rate should be 6-8 U/hour. Conversely, in small subjects or in children $2 \mathrm{U} /$ hour may be sufficient; we obtained a satisfactory result at this low rate in a patient who weighed only $42.0 \mathrm{~kg}$. Figure 2 emphasises the importance of body weight in relation to insulin dose. It might be argued that the initial infusion rate should be calculated on this basis-for example, $0.03 \mathrm{U} / \mathrm{kg} /$ hour. There is, however, a considerable scatter of insulin sensitivity at any given dose for weight. In view of this and the flexibility of the protocol, which allows an increase of infusion rate during the test, we conclude that it is preferable to divide patients into three dosage categories according to weight and clinical condition, as follows: a dose of 6-8 U/hour in patients resistant to insulin, patients with acromegaly, and obese patients; a dose of $4 \mathrm{U} /$ hour in normal sized adults with normal or underactive pituitary glands; and a dose of $2 \mathrm{U} /$ hour in children or adults of body weight less than $45 \mathrm{~kg}$.

There are a number of stimulation tests to assess secretion of growth hormone; if results are positive these tests are helpful but if negative they may require confirmation by a hypoglycaemia stress test. Reductions in blood glucose concentrations within the normal physiological range can lead to a significant release of growth hormone, ${ }^{6}{ }^{7}$ suggesting that there is no absolute threshold value of plasma glucose concentration that causes the release of counterregulatory hormones. The continuous intravenous insulin infusion may therefore offer particular advantages in the investigation of growth hormone deficiency as severe hypoglycaemia, which is undesirable and even dangerous in children, can be avoided.

We thank Dr R B Tattersall and Dr D I Johnson for allowing us to study their patients; Dr D Owen and the Novo Company Limited for providing special supplies of dilute monocomponent insulin; Dr A M J Woolfson, Mr C Selby, and the staff in the department of clinical chemistry, City Hospital, Nottingham, for performing the growth hormone and cortisol assays, and Mrs D Lake for performing the catecholamine measurements in the Medical School, Queen's Medical Centre. We also thank Miss Myra McLean for preparing the typescript.

\section{References}

1 Greenwood FC, Landon J, Stamp TCB. The plasma sugar, free fatty acid, cortisol and growth hormone response to insulin. $\mathcal{F}$ Clin Invest 1966;45: 429-49.

2 Gale EAM, Bennett T, Macdonald IA, Holst JJ, Matthews JA. The physiological effects of insulin-induced hypoglycaemia in man: responses at differing levels of blood glucose. Clin $\mathrm{Sci}$ (in press).

${ }^{3}$ Green JH, Macdonald IA. The influence of intravenous glucose on body temperature. Q $\mathcal{F}$ Exp Physiol $1981 ; 66: 465-73$.

4 Gerich J, Davis J, Lorenzi M, et al. Hormonal mechanisms of recovery from insulin-induced hypoglycaemia. Am $\mathcal{F}$ Physiol $1979 ; 236$ :E380-5.

${ }^{5}$ Gerich J, Langlois M, Noacco C, Karam J, Forsham PH. Lack of glucagon response to hypoglycaemia in diabetes. Science 1973;182:171-3.

'Santiago JV, Clarke WL, Shah SD, Cryer PE. Epinephrine, norepinephrine, glucagon and growth hormone release in association with physiological decrements in the plasma glucose concentration in normal and diabetic man. $\mathcal{f}$ Clin Endocrinol Metab 1980;51:877-83.

${ }^{7}$ Glick SM. Hypoglycaemic threshold for human growth hormone release. f Clin Endocrinol Metab 1970;30:619-23.

(Accepted 8.7une 1983) 